\title{
Frequency control of islanded microgrid using fuzzy-PI and autotuned controllers
}

Jitender Kaushal, Prasenjit Basak

Electrical and Instrumentation Engineering Department, Thapar Institute of Engineering and Technology, India

\begin{tabular}{l}
\hline \hline Article Info \\
\hline Article history: \\
Received Dec 1, 2018 \\
Revised Jan 25, 2019 \\
Accepted Feb 7, 2019 \\
\hline
\end{tabular}

Keywords:

Autotuned PI controller Fuzzy-PI controller Microgrid frequency control

\begin{abstract}
Any mismatch between generation and demand causes frequency to deviate from nominal value which affects the microgrid operation and reliability of power flow. The load frequency changes abnormally, which is fuzzy in nature, due to low system inertia and unpredictable variation in wind and solar irradiance level. So a frequency controller is needed to solve this problem meeting generation and demand of an islanded microgrid system considering the fuzziness in frequency fluctuation. This paper presents a case study of a hybrid microgrid system consisting of PV system, wind turbine generator set, diesel generator set along with storage facility and equipped with a proposed fuzzy-PI controller for frequency control under islanded condition. This controller shows satisfactory steady-state response. Further, performance of the proposed fuzzy-PI controller is verified with that of an autotuned PI controller to get faster response. The change in frequency is found minimum in case of autotuned PI controller as compared to fuzzy-PI controller. The proposed fuzzy-PI controller is validated based on ITAE $(4-7 \%)$ which is higher than that attained form autotuned-PI controller. The developed model is simulated in Matlab/Simulink environment in this case study.
\end{abstract}

Copyright (C) 2019 Institute of Advanced Engineering and Science. All rights reserved.

\section{Corresponding Author:}

Prasenjit Basak,

Electrical and Instrumentation Engineering Department,

Thapar Institute of Engineering and Technology,

Patiala, Punjab, India.

Email: prasenjit@thapar.edu

\section{INTRODUCTION}

As the power demand is increasing at an alarming rate, pressure on conventional energy resources has increased leading to depletion of fossil fuels. So, non- conventional sources such as wind, PV, fuel cells, microturbines are being used to generate electrical power [1]. Microgrid (MG) is a concept that utilizes the energy generated by these distributed energy resources. Microgrids not only help in extracting power from non-conventional resources but also improves the power reliability and helps the concept of smart grid to emerge [2]. The concept of microgrid was first introduced by an organization namely, the consortium for Electric Reliability Technology Solutions (CERTS) in 1998 [3].

There are various advantages and disadvantages associated with a microgrid. One major advantage of microgrid is that it provides clean power as there is little or negligible pollution associated with microsources unlike burning of fossil fuels which act as a major source of pollution and global warming. Secondly, these systems can be used in geographically isolated conditions where it is not possible to extract power from conventional sources and set up large plants. Hence, power can be extracted from locally available microsources like wind, biomass, solar, geothermal, etc. [4]. Output power fluctuation is one major problem associated with microgrid which further leads to frequency and voltage fluctuation. 
A microgrid can operate in two modes, namely grid connected and islanded mode [5]. In grid connected mode the MG is connected to the utility grid, whereas in islanded mode it behaves as an independent entity having no interaction with utility grid.

When operating in grid connected mode, the control of the system is majorly taken care of by utility grid. But under islanded condition the control of system is purely regulated by microgrid central controller. So, in order to ensure a continuous and reliable supply of power from microgrid, a proper control system for microgrid needs to be designed. There are various control strategies available for frequency control of microgrid; droop control is one of the conventional control strategies used for frequency restoration [6].

Nowadays intelligence-based controllers are used as the control scheme which needs to be fast and efficient. In this paper fuzzy PI based controller is used where output of fuzzy is fed as an input to PI in order to adjust the control parameters $\mathrm{P}$ and I [7].

In this case study, PV and wind generators have been used for the consideration of a MG. The power output from these two sources completely depends on climatic condition such as solar insolation and wind speed. So, a backup system is required to continue power supply at times when it is not possible to extract required power from renewable sources due to climatic variation. A diesel generator set and storage system for backup purpose has been incorporated. For storage a flywheel and battery systems are used.

\section{PROPOSED HYBRID MICROGRID SYSTEM}

A hybrid MG system has been considered as presented in [8].The proposed load frequency control model of MG is presented in Figure 1.

The Mathematical model of this system is considered and is represented in the form of transfer function [9]. All the values are considered in per unit. The p.u. values required for load frequency control (LFC) model are given in Table 1. Microgrid consists of photovoltaic system, wind turbine generator set and a diesel generator set for generating the required power. The energy storage systems used are flywheel and a battery. These storage systems store the surplus power when demand is less than the generation and provide the required power when the renewable sources are not able to cope up with the load demands. The diesel generator set can also be used to meet load demands when power generated by PV and wind system is insufficient. The flywheel system, battery storage system and diesel generator system can also be termed as backup systems.

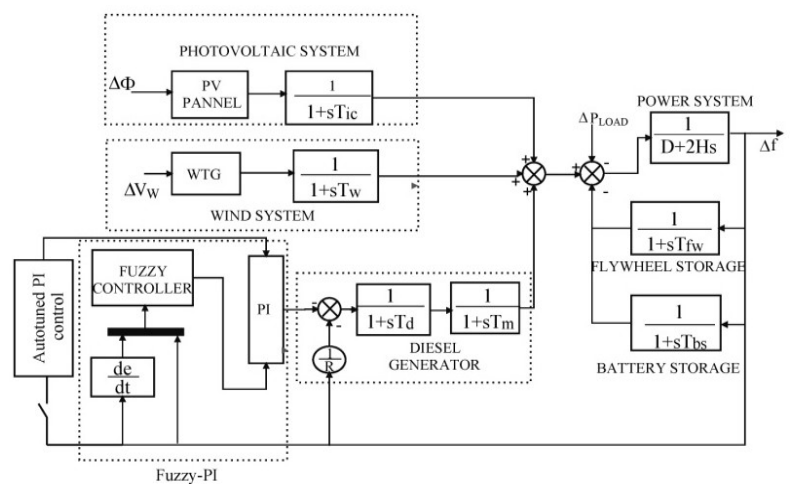

Figure 1. A Proposed hybrid microgrid model

The net power generated $\left(P_{n e t}\right)$ can be expressed by (1)

$$
P_{n e t}=P_{P V}+P_{W T G}+P_{D E G} \pm P_{B E S} \pm P_{F E S}
$$

where, $P_{P V}$ is power generated by PV system, $P_{W T G}$ is power generated by WTG, $P_{D E G}$ is power of DEG, $P_{B E S}$ is power of battery storage system, $P_{F E S}$ is power of flywheel system.

For simulation purpose a load of $350 \mathrm{~kW}$ is considered and rated power of all generating units used in microgrid system is presented in Table 2.

Frequency control of islanded microgrid using fuzzy-pi and autotuned controllers (Jitender Kaushal) 
Table 1. Parameters for proposed model

\begin{tabular}{cc}
\hline Parameters & Value $(\mathrm{pu})$ \\
\hline $\mathrm{T}_{\mathrm{m}}$ & 0.42 \\
$\mathrm{~T}_{\mathrm{d}}$ & 0.081 \\
$\mathrm{~T}_{\mathrm{ic}}(\mathrm{s})$ & 0.004 \\
$\mathrm{~T}_{\mathrm{fw}}(\mathrm{s})$ & 0.1 \\
$\mathrm{~T}_{\mathrm{bs}}(\mathrm{s})$ & 0.12 \\
$\mathrm{R}(\mathrm{Hz} / \mathrm{pu})$ & 3 \\
$\mathrm{D}(\mathrm{pu} / \mathrm{Hz})$ & 0.0156 \\
$\mathrm{~T}_{\mathrm{i}}(\mathrm{s})$ & 0.041 \\
$2 \mathrm{H}(\mathrm{pu} / \mathrm{s})$ & 0.166 \\
\hline
\end{tabular}

Table 2. Power ratings of generating units

\begin{tabular}{cc}
\hline Generating unit & Rated power $(\mathrm{kW})$ \\
\hline PV panel & 30 \\
WTG & 100 \\
Diesel gen set & 160 \\
Battery storage & 45 \\
Flywheel storage & 45 \\
Applied load & 350 \\
\hline
\end{tabular}

\subsection{Photovoltaic system}

Photovoltaic is a specialized term for sun-oriented vitality. PV cells are generally made of silicon material that discharges electrons when presented to light. The measure of electron discharge depends upon the power of light occurrence on it. This Silicon is secured with matrix that aids electrons specifically bearing to deliver electric current. These currents are guided into wire which is associated with battery or DC apparatus to convert the DC into AC [10]. Block diagram of a PV system is represented in Figure 2. For analysis purpose the rating of $\mathrm{PV}$ module used is $150 \mathrm{~W}$. Maximum current and voltage are $4.35 \mathrm{~A}$ and $34.5 \mathrm{~V}$ respectively, which produce a maximum power of $150.07 \mathrm{~W}$.

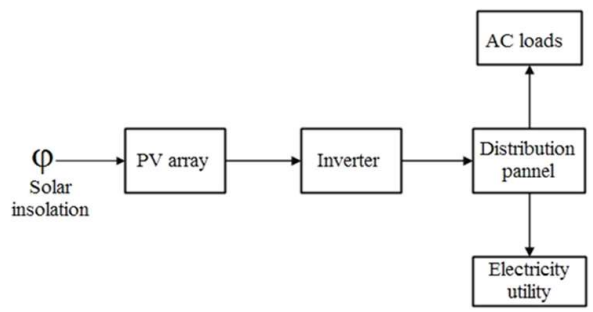

Figure 2. Block diagram of PV system

The transfer function for PV system is given as in (2)

$$
G_{P V}=\frac{K_{P V}}{1+s T_{P V}}=\frac{\Delta P_{P V}}{\Delta \Phi}
$$

where, $\Delta P_{P V}=$ Change in output power of PV system, $\Delta \Phi=$ Change in solar irradiation. For analysis purpose change in solar irradiation is considered using a step function.

\subsection{Wind generator system}

The wind generator system produces power by the virtue of blowing winds. The energy encapsulated by the blowing winds is used to run the wind generator set as shown in Figure 3. The output power produced by wind turbine generator set totally depends upon velocity of wind. For the purpose of simulation, the wind speed is assumed to be constant $10 \mathrm{~m} / \mathrm{s}$; and it delivers a constant power of $100 \mathrm{~kW}$ to the microgrid [11].

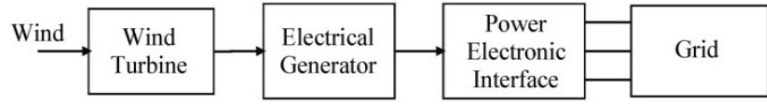

Figure 3. Block diagram of WTG set

The (3) represents the transfer function for wind generator system

$$
G_{W T G}=\frac{K_{W T G}}{1+s T_{W T G}}=\frac{\Delta P_{W T G}}{\Delta P_{W}}
$$

Int. J. of Adv. in Appl. Sci. Vol. 8, No. 1, March 2019: 64 - 72 
where,

$\Delta P_{W T G}=$ Change in output power of wind generator system.

$\Delta P_{W}=$ Change in mechanical power of wind turbine.

\subsection{Diesel generator set}

Diesel generator set is used to ensure the continuous supply of power, when the PV and wind systems are not able to cope up with the power demand; the extra power demand is met by Diesel engine generator. Fuel consumption in diesel engine model depends upon mechanical power input and speed [12]. The governor adjusts the fuel inrush and thus regulates the power output of engine and generator. This helps in frequency restoration and the controller unit is used in conjugation with diesel model. The transfer function for DEG is presented in (4).

$$
G_{D E G}=\frac{K_{D E G}}{1+s T_{D E G}}=\frac{\Delta P_{D E G}}{\Delta f}
$$

where,

$\Delta P_{D E G}=$ Change in output power of DEG, $\Delta f=$ Deviation in system frequency.

\subsection{Storage system}

Battery and flywheel systems are used for storage purpose; they play a vital role in maintaining system stability [13].When the power generated by renewable sources is in surplus; it is captured and stored by storage systems. The stored energy is delivered back to the system when power generated by renewable sources is insufficient to meet load demand. The (5) and (6) represent transfer function for flywheel and battery storage system respectively.

$$
G_{F E S}=\frac{K_{F E S}}{1+S T_{F E S}}=\frac{\Delta P_{F E S}}{\Delta f}
$$

where,

$\triangle P_{F E S}=$ Change in exchanged power of flywheel system.

$\Delta f=$ System frequency deviation

$$
G_{B E S}=\frac{K_{B E S}}{1+s T_{B E S}}=\frac{\Delta P_{B E S}}{\Delta f}
$$

$\Delta P_{B E S}=$ Change in exchanged power of batter storage system, $\Delta f=$ Deviation in system frequency.

\subsection{Power system: utility side}

There are two important terms associated with power system such as inertia and power oscillation damping. Reliability of any power plant depends upon the inertia associated with large rotating masses. The imbalance between supply and demand of power system is overcome by managing inertia. Damping in system could occur on account of any abnormal condition in the system.

Transfer function for microgrid system is represented by (7)

$$
\Delta f=\frac{1}{D+2 H s}
$$

where, $D=$ Load damping constant, $2 H=$ inertia constant

\section{RESEARCH METHOD: MICROGRID FREQUENCY CONTROL METHODOLOGIES}

A lot of frequency control techniques for microgrid are available. Earlier techniques, like frequency droop control, tie line frequency control is presented in many literatures. These systems are slow, complex and not very efficient. With advancements in power system, the need for intelligent controllers has emerged. In this case study fuzzy-PI controller is used. The frequency error and rate of change of error are provided as input to the fuzzy controller and the output of fuzzy is provided as input to PI controller. The fuzzy-PI controller is validated using autotuned- PI controller in the Matlab-Simulink environment.

\subsection{Fuzzy based PI control}

For a PI controller the values of P and I are generally pre-assigned. If any fluctuation occurs in the system, model of the PI controller is not able to take account of them and hence the performance of controller degrades. Therefore, we use fuzzy based PI controller which provides an intelligent control by updating the

Frequency control of islanded microgrid using fuzzy-pi and autotuned controllers (Jitender Kaushal) 
PI controller parameters if there is any variation in system operation condition. As represented in Figure 4 fuzzy system output is provided as an input to PI controller which further controls the plant with updated values of $\mathrm{P}$ and $\mathrm{I}$.

The fuzzy inputs i.e. the error and change in error are provided to fuzzy logic controller. They are fuzzified using seven membership functions Positive big (PB), Positive medium (PM), Positive small (PS), Zero (ZE), Negative big (NB), Negative medium (NM), Negative small (NS). The membership functions for input and output are depicted in Figure 5. A fuzzy controller consists of following four main elements [14].

\subsubsection{Fuzzification}

It is the process of converting the user inputs provided to controller into a form that inference system can implement the provided rules.

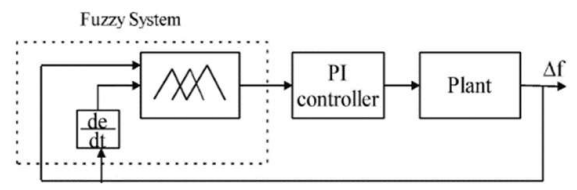

Figure 4. Control structure of fuzzy-PI system

\subsubsection{Rule base}

It is a set of 'if' and 'then' rules, which consists the fuzzy logic representation of user's description on attaining the best possible control. Rule base for proposed control scheme is represented in Table 3 .

\subsubsection{Inference mechanism}

It imitates the user's idea of attaining a best possible control, in order to understand and apply the rules for achieving a good control.

Table 3. Rules for proposed fuzzy-PI controller

\begin{tabular}{cccccccc}
\hline $\begin{array}{c}\mathrm{K}_{\mathrm{p}} \\
\mathrm{K}_{\mathrm{i}}\end{array} \begin{array}{c}\mathrm{e} \\
\mathrm{ce}\end{array}$ & $\mathrm{NB}$ & $\mathrm{NM}$ & $\mathrm{NS}$ & $\mathrm{ZE}$ & $\mathrm{PS}$ & $\mathrm{PM}$ & $\mathrm{PB}$ \\
\hline \multirow{2}{*}{$\mathrm{NB}$} & $\mathrm{N}$ & $\mathrm{Z}$ & $\mathrm{N}$ & $\mathrm{N}$ & $\mathrm{N}$ & $\mathrm{Z}$ & $\mathrm{P}$ \\
& $\mathrm{P}$ & $\mathrm{Z}$ & $\mathrm{N}$ & $\mathrm{N}$ & $\mathrm{N}$ & $\mathrm{Z}$ & $\mathrm{P}$ \\
$\mathrm{NM}$ & $\mathrm{P}$ & $\mathrm{P}$ & $\mathrm{Z}$ & $\mathrm{N}$ & $\mathrm{Z}$ & $\mathrm{P}$ & $\mathrm{P}$ \\
& $\mathrm{P}$ & $\mathrm{Z}$ & $\mathrm{Z}$ & $\mathrm{N}$ & $\mathrm{Z}$ & $\mathrm{Z}$ & $\mathrm{P}$ \\
$\mathrm{NS}$ & $\mathrm{P}$ & $\mathrm{P}$ & $\mathrm{Z}$ & $\mathrm{N}$ & $\mathrm{Z}$ & $\mathrm{P}$ & $\mathrm{P}$ \\
& $\mathrm{P}$ & $\mathrm{P}$ & $\mathrm{Z}$ & $\mathrm{N}$ & $\mathrm{Z}$ & $\mathrm{P}$ & $\mathrm{P}$ \\
$\mathrm{Z}$ & $\mathrm{P}$ & $\mathrm{P}$ & $\mathrm{P}$ & $\mathrm{Z}$ & $\mathrm{P}$ & $\mathrm{P}$ & $\mathrm{P}$ \\
& $\mathrm{P}$ & $\mathrm{P}$ & $\mathrm{P}$ & $\mathrm{Z}$ & $\mathrm{P}$ & $\mathrm{P}$ & $\mathrm{P}$ \\
$\mathrm{TS}$ & $\mathrm{P}$ & $\mathrm{P}$ & $\mathrm{Z}$ & $\mathrm{N}$ & $\mathrm{Z}$ & $\mathrm{P}$ & $\mathrm{P}$ \\
& $\mathrm{P}$ & $\mathrm{P}$ & $\mathrm{Z}$ & $\mathrm{N}$ & $\mathrm{Z}$ & $\mathrm{P}$ & $\mathrm{P}$ \\
$\mathrm{PM}$ & $\mathrm{P}$ & $\mathrm{P}$ & $\mathrm{Z}$ & $\mathrm{N}$ & $\mathrm{Z}$ & $\mathrm{P}$ & $\mathrm{P}$ \\
& $\mathrm{P}$ & $\mathrm{Z}$ & $\mathrm{Z}$ & $\mathrm{N}$ & $\mathrm{Z}$ & $\mathrm{Z}$ & $\mathrm{P}$ \\
$\mathrm{PB}$ & $\mathrm{P}$ & $\mathrm{Z}$ & $\mathrm{N}$ & $\mathrm{N}$ & $\mathrm{P}$ & $\mathrm{Z}$ & $\mathrm{P}$ \\
& $\mathrm{P}$ & $\mathrm{Z}$ & $\mathrm{N}$ & $\mathrm{N}$ & $\mathrm{P}$ & $\mathrm{Z}$ & $\mathrm{P}$ \\
\hline
\end{tabular}

\subsubsection{Defuzzification}

It is the process which finally provides the input to the system, by converting the decision of inference system.

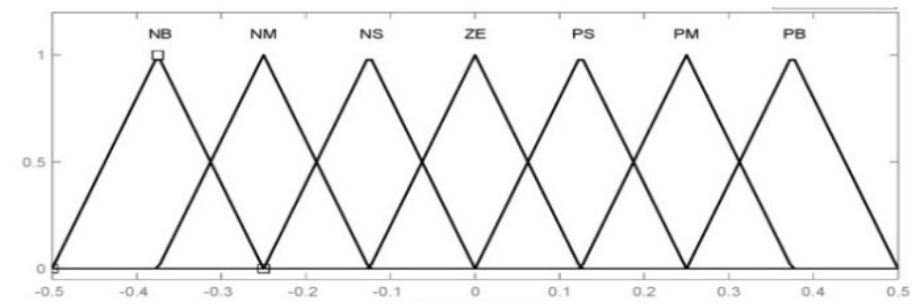

(a)

Int. J. of Adv. in Appl. Sci. Vol. 8, No. 1, March 2019: 64 - 72 


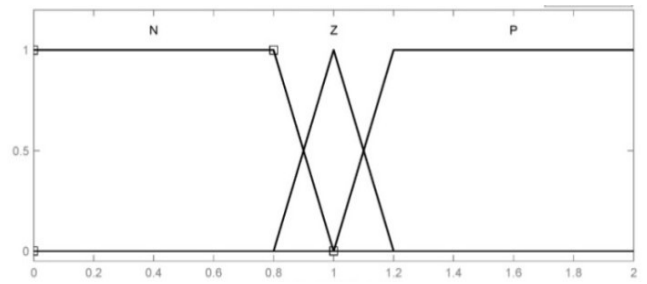

(b)

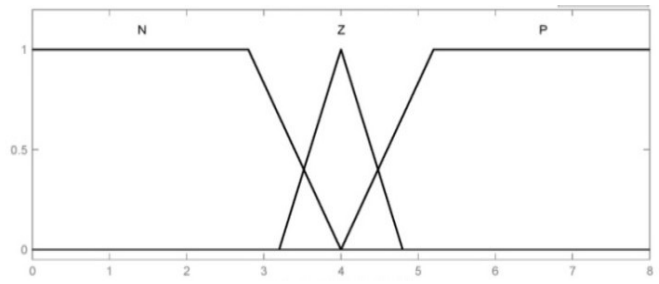

(c)

Figure 5. Membership function of (a) error or change in error (b) $\mathrm{K}_{\mathrm{p}}(\mathrm{c}) \mathrm{K}_{\mathrm{i}}$

\subsection{Autotuned PI}

Autotuning is a process that automatically computes the value of control parameters for any given system to bring out the best possible control without user interaction. It is much more efficient and reliable as compared to manual computation of parameters.

Autotuning process basically includes three main steps:

a. Choosing the model to be processed.

b. Collecting the data associated with the process and fitting it into the model.

c. Computing the control parameters.

The process identification is done basically by two methods; such as step response method and relay feedback method. The data about the process can be provided either by triggering the process intentionally or by observing the process behaviour under normal conditions. After the attainment of data, it is converted into process description. The tuning rules can be formulated in three ways:

a. Tuning the parameters in such a way that the process output matches with the reference model used.

b. Computing parameters based on some closed loop system description.

c. Tuning based on human description.

All these methods are based on solving a certain set of equations. The detailed process of Autotuning is presented in [15]. The tuning of PI controller is done automatically using the PI controller block readily available in MATLAB/Simulink library. The tuned values of P and I attained are 1.4999 and 8.7186 respectively.

\subsubsection{Controller modes}

PI controller uses proportional (P) mode and integral mode (I) for computing a control signal. The PI control signal is computed as given in (8).

$$
u(t)=K_{P} e(t)+K_{i} \int e(t) d t
$$

The above equation can be written in equivalent form as

$$
u(t)=K\left(e(t)+\frac{1}{T_{i}} \int e(t) d t\right)
$$

\section{a. Proportional mode}

The control law for proportional mode is given by

$$
u_{p}(t)=K e(t)+U_{b}
$$

here, $u_{p}(t)$ is the output of proportional controller, $K$ represents the gain of the system and $U_{b}$ is the bias or reset value.

The $\mathrm{P}$ makes the action of controller proportional to the error. The $\mathrm{P}$ action depends on instantaneous values of error. Only for non-zero values of error the output value of controller will be nonzero. This means that the value of $\mathrm{P}$ at steady state will be zero, but this is not feasible. So, in order to maintain value of $\mathrm{P}$ controller at a constant level a bias is added to the system. Which means that even if value of error is zero the value of controller output will be some constant and hence maintain the controller action. But if an integral controller is used in conjugation with $\mathrm{P}$ controller, then there is no need to add an external bias. The reset is attained by action of I controller. Some characteristics of proportional control are stated below.

Frequency control of islanded microgrid using fuzzy-pi and autotuned controllers (Jitender Kaushal) 
- Increasing the value of P control will reduce the steady state error.

- Increasing the value of $\mathrm{P}$ beyond certain point will only result in increased overshoot.

- It helps in reducing the rise time

\section{b. Integral mode} given as:

The output generated by integral action is proportional to accumulated error. The I-control signal is

$$
u_{1}(t)=\frac{K}{T_{i}} \int e(t)+u(0)
$$

here;

$T_{i}$ is the reset time or integral time constant and $u(0)$ is the output of controller at $\mathrm{t}=0$.

The integral controller considers the sum of all the errors. When input of integrator is e, steady state cannot be achieved unless e is non-zero. So, it ensures a zero error at steady state. The I-control not only considers the present value of error but also accounts for the previous value of error. The action of I controller is slow, and it does not respond to sudden changes quickly.

Some key features of the I-controller are:

- It helps in eliminating the steady state error.

- Increasing the value of I beyond certain limit leads to increase in overshoot.

- It reduces the rise time.

\section{RESULTS AND DISCUSSION}

For performing simulations three different cases have been considered by varying input signals of PV, wind and change in load. In the case studies, to carry out comparative analysis of Fuzzy PI controller and autotuned PI controller, the results for both the schemes have been depicted. The effectiveness of proposed control scheme is illustrated by simulating the model in MATLAB/Simulink environment using Sim-Power blocks.

\section{Case Study 1}

The model is simulated by considering a disturbance of $0.2 \mathrm{pu}$ in load and keeping other two signals i.e. solar insolation and wind speed constant to value of $1000 \mathrm{~W} / \mathrm{m}^{2}$ and $10 \mathrm{~m} / \mathrm{s}$ respectively. Both the systems are studied and the values of ITAE (Integral of time absolute error) are observed. The outputs for both the schemes are presented in Figure 6 (a) and (b). It is noted that the values of ITAE in both cases is relatively same. The autotuned scheme has shown fast response time and steady-state level compared to fuzzy-PI.

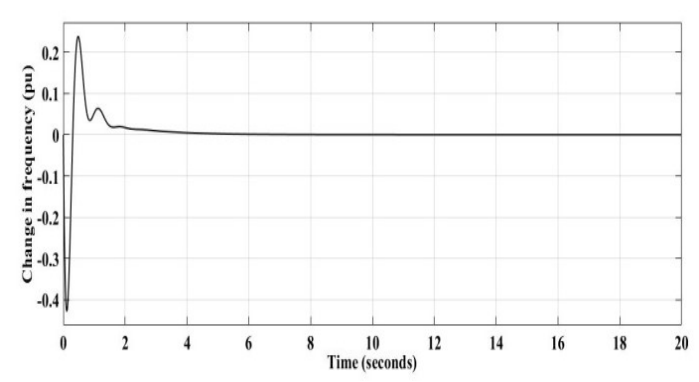

(a)

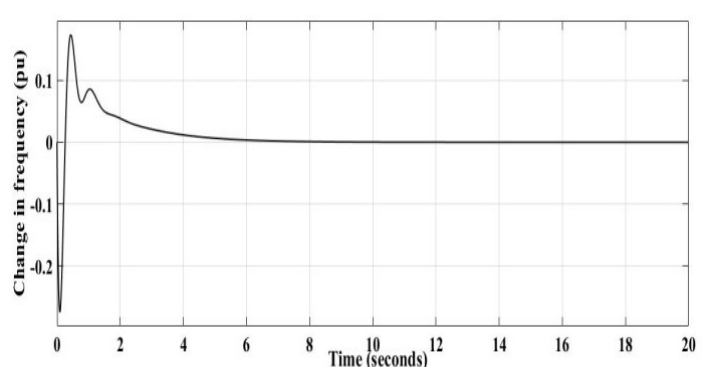

(b)

Figure 6. Change in frequency vs. time graph for (a) autotuned-PI controller (b) fuzzy-PI controller

\section{Case Study 2}

Under second case the wind speed is assumed to be constant $10 \mathrm{~m} / \mathrm{s}$ and a change of $0.2 \mathrm{pu}$ in both load and PV system is considered. The response for autotuned and Fuzzy-PI scheme is presented in Figure 7 (a) and (b) respectively. The values for control parameters and ITAE are presented in Table 4. It can be

Int. J. of Adv. in Appl. Sci. Vol. 8, No. 1, March 2019: 64 - 72 
inferred from the values that error in case of autotuned PI is less than that in fuzzy-PI control scheme. But the fuzzy-PI scheme also generates a good response based on the referred system problem.

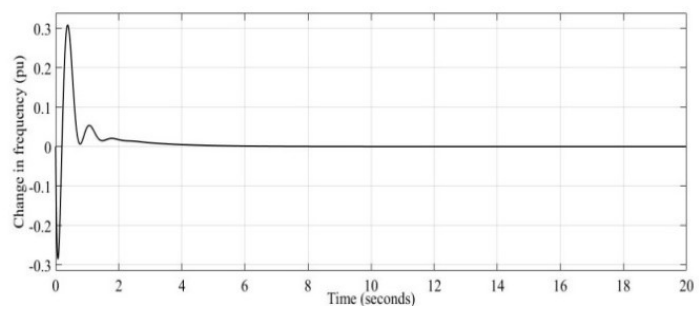

(a)

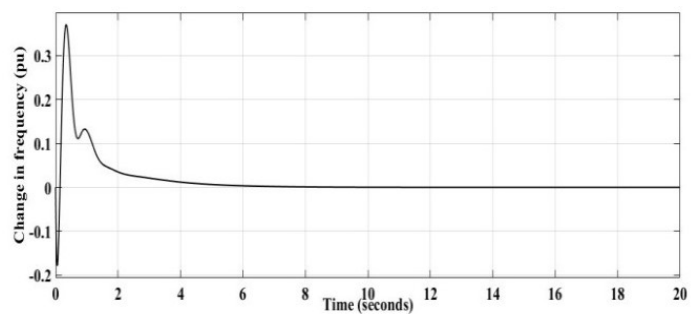

(b)

Figure 7. Change in frequency vs. time graph for (a) autotuned PI (b) fuzzy-PI control scheme

\section{Case Study 3}

The simulation in this case is done where change in all three signals i.e. load, solar insolation and wind speed of $0.2 \mathrm{pu}$ are considered. Based on the simulation results presented in Figure 8 (a) and 8 (b) it can be inferred that the peak values in both the cases are almost same. The autotuned controller improves the performance of system with minimum value of ITAE. But the value of ITAE for Fuzzy-PI is also close to that obtained while using autotuned controller. The mapping between autotuned and fuzzy based PI controller is presented in Figure 9 corresponding to ITAE. It is observed that value of ITAE in autotuned-PI controller is less as compared to fuzzy-PI controller for all three cases.

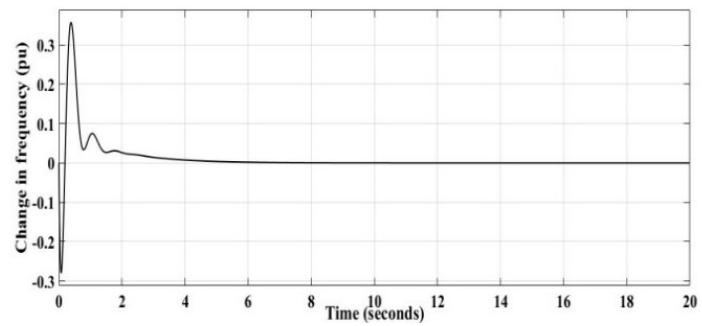

(a)

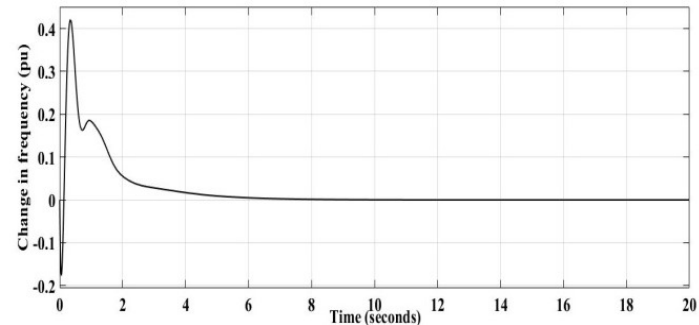

(b)

Figure 8. Change in frequency vs. time graph for (a) autotuned PI (b) Fuzzy-PI controller

Table 4. PI controller parameters

\begin{tabular}{lllllll}
\hline & \multicolumn{3}{c}{ Autotuned PI } & \multicolumn{3}{c}{ Fuzzy-PI } \\
& $\mathrm{P}$ & $\mathrm{I}$ & $\mathrm{ITAE}(\%$ age) & $\mathrm{P}$ & $\mathrm{I}$ & ITAE (\%age) \\
\hline 1 & 1.4999 & 8.7186 & 0.1808 & 1.000011 & 7.000045 & 0.1944 \\
2 & 1.4999 & 8.7186 & 0.176 & 1.000048 & 7.000192 & 0.1886 \\
3 & 1.4999 & 8.7186 & 0.2045 & 1.000028 & 7.000810 & 0.2137 \\
\hline
\end{tabular}

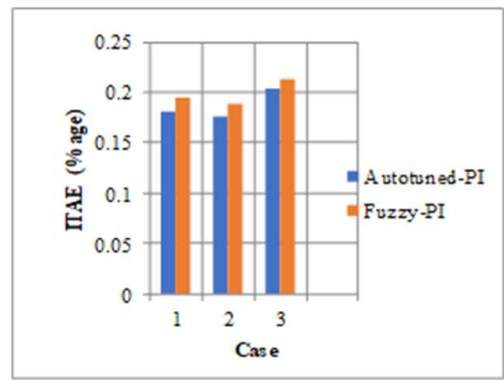

Figure 9. Mapping of autotuned and fuzzy-PI based on ITAE 


\section{CONCLUSION}

The integration of DER's into a microgrid system consisting of varying load can cause a frequency fluctuation issue. So, to resolve this, fuzzy-PI based controller is designed to minimize the frequency deviation in the system. In this case study, the performance of controller is evaluated by considering three different cases of disturbance, by causing variation in input signal to PV panel, wind speed and change in load. Further the proposed scheme is compared with autotuned-PI control where PI parameters are automatically tuned for the readily available controller. In this case study, it is evident from the results that both the schemes generate satisfactory results. The overshoots in both cases are being relatively same. The case study results show that the autotuned PI controller performs better than fuzzy-PI controller by generating a faster steady state response. The value of ITAE in case of autotuned PI controller is observed less as compared to fuzzy-PI controller. In future proposition the autotuned and fuzzy-PI control technique would be used in case of two-area hybrid microgrid system.

\section{REFERENCES}

[1] R. H. Lasseter, "Dynamic Distibution using (DER) distributed energy resources," Proc. IEEE Power Eng. Soc. Transm. Distrib. Conf., pp. 932-934, 2006.

[2] T. Senjyu, T. Nakaji, K. Uezato, and T. Funabashi, "A Hybrid Power System Using Alternative Energy Facilities in Isolated Island,” IEEE Trans. Energy Convers., vol. 20, no. 2, pp. 406-414, 2005.

[3] H. Nikkhajoei and R. H. Lasseter, "Distributed generation interface to the CERTS microgrid," IEEE Trans. Power Deliv., vol. 24, no. 3, pp. 1598-1608, 2009.

[4] S. Baudoin, I. Vechiu, and H. Camblong, "A review of voltage and frequency control strategies for islanded microgrid," Syst. Theory, Control Comput. (ICSTCC), 2012 16th Int. Conf., vol. 33, no. 0, pp. 1-5, 2012.

[5] J. A. P. Lopes, C. L. Moreira, and A. G. Madureira, "Defining control strategies for microgrids islanded operation," IEEE Trans. Power Syst., vol. 21, no. 2, pp. 916-924, 2006.

[6] A. Klem, M. H. Nehrir, and K. Dehghanpour, "Frequency stabilization of an islanded microgrid using droop control and demand response," 2016 North American Power Symposium (NAPS), Denver, CO, pp. 1-6, 2016.

[7] M. S. Bisht and Sathans, "Fuzzy based intelligent frequency control strategy in standalone hybrid AC microgrid," 2014 IEEE Conference on Control Applications (CCA), Juan Les Antibes, pp. 873-878, 2014.

[8] Maneesh, "Frequency control of a microgrid by using PI controller," 2015 Int. Conf. Energy, Power Environ. Towar. Sustain. Growth, ICEPE 2015, 2016.

[9] D. J. Lee and L. Wang, "Small-signal stability analysis of an autonomous hybrid renewable energy power generation/energy storage system part I: Time-domain simulations," IEEE Trans. Energy Convers., vol. 23, no. 1, pp. 311-320, 2008.

[10] S. Satapathy, K. M. Dash, and B. C. Babu, "Variable step size MPPT algorithm for photo voltaic array using zeta converter - A comparative analysis," 2013 Students Conf. Eng. Syst. SCES 2013, 2013.

[11] P. Wang and R. Billinton, "Reliability benefit analysis of adding WTG to a distribution system," IEEE Trans. Energy Convers., vol. 16, no. 2, pp. 134-139, 2001.

[12] G. S. Stavrakakis and G. N. Kariniotakis, "A general simulation algorithm for the accurate assessment of isolated diesel-wind turbines systems interaction. I. A general multimachine power system model," in IEEE Transactions on Energy Conversion, vol. 10, no. 3, pp. 577-583, 1995.

[13] S. Singh, M. Singh, and S. C. Kaushik, "Optimal power scheduling of renewable energy systems in microgrids using distributed energy storage system," IET Renew. Power Gener, 2016.

[14] M. S. Bisht and Sathans, "Fuzzy based intelligent frequency control strategy in standalone hybrid AC microgrid," 2014 IEEE Conf. Control Appl. CCA 2014, pp. 873-878, 2014.

[15] C. Andersson and M. Lindberg, "Autotuning of a PID-controller," October, p. 38, 2004.

Int. J. of Adv. in Appl. Sci. Vol. 8, No. 1, March 2019: 64 - 72 